neste ano de 2021, e em plena pandemia, Mulheres na Ciência distingue 101 investigadoras. Esta iniciativa teve como objetivo dar continuidade às homenagens a mulheres cientistas portuguesas iniciadas em 2016. Das 101 mulheres fotografadas por Clara Azevedo, José Carlos Carvalho, Luís Filipe Catarino e Rita Carmo, 11 têm ligaçcões às áreas da química e afins, mas todas exibem uma forte paixão pela sua "Ciência", uma dedicação extrema e constituem assim uma grande motivação e uma fonte de inspiração para outras jovens investigadoras seguirem esta vocação.
Com o entusiasmo que lhe é característico poderá rever a intervenção de Rosalia Vargas, Presidente da Ciência Viva, assim como o programa completo do evento em cienciaviva.pt/divulgaca-cientifica/muIheresnaciencia/dia-internacional-da-mulher.

$>$

Maria José Lourenço

mjlourenco@ciencias.ulisboa.pt

\section{Training School on Mechanochemistry: From Supramolecular to Covalent Bonds}

De 22 a 25 de março de 2021 decorreu em formato online, com difusão a partir de Lisboa, a ação de formação avançada "Training school on Mechanochemistry: From supramolecular to covalent bonds", realizada no âmbito da ação COST Mechanochemistry for Sustainable Industry (Mech@SustInd, CA18112, mechsustind.eu), na qual participaram alunos e professores de 15 nacionalidades diferentes. Esta ação COST, da qual fazem parte Teresa Duarte (CQE, IST/UL), Vânia André (CQE, IST/UL), Clara Gomes (LAQV-REQUIMTE, FCT NOVA) (organizadoras desta escola) e Maria de Fátima Minas da Piedade (CQE, IST/UL) e Mafalda Sarraguça (LAQV-REQUIMTE, FF/ UP), tem como objetivo harmonizar a investigação fundamental e aplicada com a inovação tecnológica e as necessidades de uma indústria mais sustentável. Este processo envolve não só a formação de uma nova geração de especialistas nesta área, mas também a promoção do estudo da mecanoquímica e o incentivo à sua utilização em processos de produção, catalisando novas estratégicas para a indústria química europeia, culminando a longo prazo no desenvolvimento de uma economia mais verde e mais competitiva.

Esta escola contou com a participação de docentes e investigadores de diferentes centros de investigação nacionais e internacionais, lecionando nas suas áreas de especialização: CQE, IST/UL e FCUL: Ana Paula Ribeiro, Auguste Fernandes, Ermelinda Maçôas, Her-

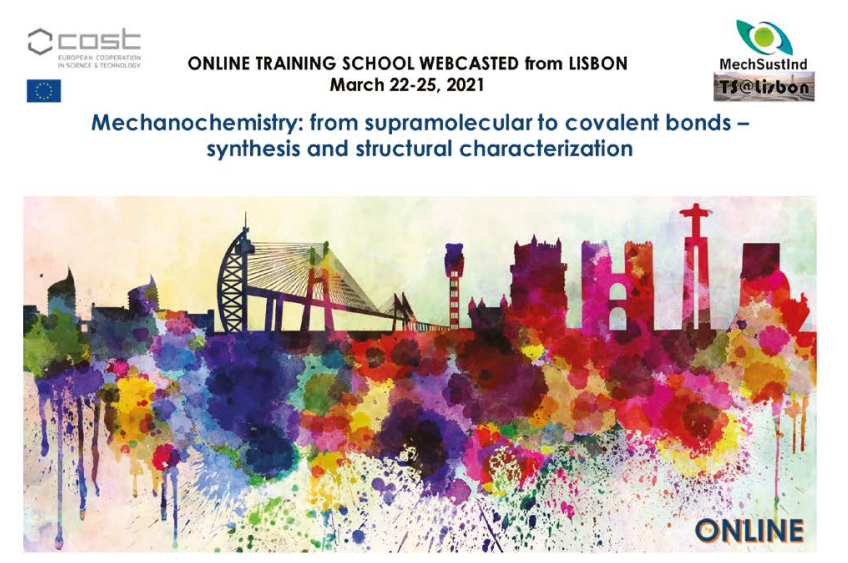

mínio Diogo, Maria de Fátima Minas da Piedade, Maria João Ferreira, Luísa Martins; iBB, IST/UL: Vasco D. B. Bonifácio; CICECO, UA: Luís Mafra; LAQV-REQUIMTE, FF/UP: Mafalda Sarraguça; CQC, UC: Marta Piñeiro; Novosibirsk State University, Rússia: Elena Boldyreva; McGill University, Canadá: Tomislav Friscic; University of Bologna, Itália: Fabrizia Grepioni; University of Copenhagen, Dinamarca: Inês C. B. Martins; University of Montpellier, França: Evelina Colacino.

Para além das aulas teóricas, disponibilizaram-se vários módulos com demonstrações práticas sobre diferentes aplicações da mecanoquímica na síntese de pequenas moléculas e materiais avançados. Foram ainda apresentadas diferentes abordagens do uso da mecanoquímica, desde a moagem manual à utilização de diferentes tipos de moinhos, complementadas com as principais técnicas de caracterização estrutural (Difração de raios-X em pós e monocristal, ATR-FTIR, Raman, TGA-DSC e ssNMR).

\section{Vasco Bonifácio}

vasco.bonifacio@tecnico.ulisboa.pt 